\title{
Clinical Pharmacology of Bronchodilator Medications
}

\author{
Dennis M Williams PharmD BCPS AE-C and Bruce K Rubin MEngr MD MBA FAARC
}

\author{
Introduction \\ $\boldsymbol{\beta}_{2}$ Adrenergic Receptors \\ History \\ Structure and Function \\ Isomer Chemistry \\ Selectivity and Specificity \\ Pharmacodynamics and Pharmacokinetics of $\boldsymbol{\beta}_{\mathbf{2}}$ Adrenergic Agonists \\ Desensitization and Tolerance \\ Adverse and Off-Target Effects \\ Drug Interactions \\ Safety of Inhaled $\beta_{2}$ Agonists \\ Cholinergic (Muscarinic) Receptors \\ History \\ Structure and Function \\ Pharmacodynamics and Pharmacokinetics \\ Adverse and Off-Target Effects \\ Drug Interactions \\ Therapeutic Administration of Bronchodilator Medications \\ Bronchodilator Therapy for Airways Diseases \\ Asthma \\ COPD \\ Bronchiolitis \\ Cystic Fibrosis \\ Research and Development of Bronchodilators \\ Summary
}

\begin{abstract}
Obstructive lung diseases, including asthma and COPD, are characterized by air-flow limitation. Bronchodilator therapy can often decrease symptoms of air-flow obstruction by relaxing airway smooth muscle (bronchodilation), decreasing dyspnea, and improving quality of life. In this review, we discuss the pharmacology of the $\beta$ agonist and anticholinergic bronchodilators and their use, particularly in asthma and COPD. Expanding knowledge of receptor subtypes and G-protein signaling, agonist and antagonist specificity, and drug delivery have led to the introduction of safer medications with fewer off-target effects, medications with longer duration of action that may improve adherence, and more effective and efficient aerosol delivery devices. Key words: beta agonists; anticholinergic medications; muscarinic antagonists; aerosol delivery; clinical pharmacology; asthma. [Respir Care 2018;63(6):641-654. (C) 2018 Daedalus Enterprises]
\end{abstract}

\section{Introduction}

The bronchial smooth muscle of the airways is directly innervated by the parasympathetic nervous system where cholinergic receptors control bronchomotor tone. ${ }^{1}$ There is no direct sympathetic innervation of the airways, although they are rich in $\beta_{2}$ adrenergic receptors. Cholinergic and adrenergic receptors are major targets for bronchodilator therapy. Bronchodilation can be achieved through 2 primary and complementary mechanisms. The activation of $\beta_{2}$ receptors results directly in relaxation of smooth muscle. Muscarinic receptor antagonists, or anticholinergic therapies, are competitive antagonists of acetylcholine $(\mathrm{ACH})$ at postganglionic nerve receptors, resulting in smooth muscle relaxation and bronchodilation. ${ }^{2}$ 


\section{$\boldsymbol{\beta}_{2}$ Adrenergic Receptors}

\section{History}

As far back as 3000 BCE, the Chinese used ephedrine, from the plant Ephedra vulgaris, to make ma huang to treat dyspnea. ${ }^{3}$ In the 1800 s, research focused on adrenal gland extracts. By 1903, epinephrine was being administered subcutaneously for treating asthma, although it was not until 1907 that its bronchodilation properties were appreciated. ${ }^{4,5}$ Injectable aqueous epinephrine, in conjunction with an epinephrine suspension, was commonly used in the emergency management of bronchospasm until the early 1980s. Epinephrine has also been administered as an aerosol for more than a century. ${ }^{6}$

In the 1950s, the first $\beta$-selective (but $\beta$-subtype nonselective) inhaled agents, isoproterenol and isoetharine, were developed as aerosol therapies for asthma. ${ }^{7}$ Synthetic analogues of naturally occurring catecholamines were subsequently developed, and these had greater selectivity for the $\beta_{2}$ subtype receptor and, in some cases, extended durations of effect. These emerged in the early 1980s, with the introduction of metaproterenol and albuterol (salbutamol) as rapid- and short-acting therapy for acute asthma. By the mid-1990s, long-acting $\beta$ agonists were introduced, which allowed for once or twice daily dosing.

\section{Structure and Function}

Although adrenergic receptors are present throughout the body, the most clinically relevant $\beta$-mediated effects occur in cardiac muscle, bronchial and uterine smooth muscle, and skeletal muscle (Table 1). The $\alpha$ and $\beta$ receptor subtypes were first described 70 years ago. ${ }^{8}$ The $\alpha$ receptors were thought primarily to have excitatory functions, and $\beta$ receptors inhibitory function, except in the myocardium. $\beta$ receptors subtypes 1 and 2 were identified, ${ }^{9}$ with $\beta_{1}$ receptors present in cardiac muscle and

Dr Williams is affiliated with the University of North Carolina Eshelman School of Pharmacy, Chapel Hill, North Carolina. Dr Rubin is affiliated with The Children's Hospital of Richmond at Virginia Commonwealth University, Richmond, Virginia.

Dr Rubin presented a version of this paper at the 56th RESPIRATORY CARE Journal Conference, Respiratory Medications for COPD and Adult Asthma: Pharmacologic Actions to Clinical Applications, held June 22-23, 2017, in St Petersburg, Florida.

The authors have disclosed no conflicts of interest.

Correspondence: Bruce K Rubin MEngr MD MBA FAARC, Children's Hospital of Richmond at Virginia Commonwealth University, 1000 East Broad St, Richmond, VA 23298. E-mail: bruce.rubin@vcuhealth.org.

DOI: $10.4187 /$ respcare.06051
Table 1. Systemic Effects of Inhaled Beta Agonists

\begin{tabular}{ll}
\hline \hline \multicolumn{1}{c}{ Organ System } & \multicolumn{1}{c}{ Observed Adverse Effect } \\
\hline Cardiovascular & Tachycardia and palpitations \\
Central nervous system & Headache, insomnia, nervousness, dizziness \\
Gastrointestinal & Nausea, vomiting \\
Musculoskeletal & Tremor, leg cramps \\
Biochemical & Hypokalemia, hyperglycemia \\
Reproductive & Uterine relaxation \\
\hline
\end{tabular}

intestinal smooth muscle, and $\beta_{2}$ receptors in bronchial, uterine, and vascular smooth muscle. A third subtype, $\beta_{3}$, is present in adipose tissue.

The $\beta$ receptor is a classic G-protein-coupled receptor (GPCR) with an extracellular N-terminus, traversing the membrane 7 times (transmembrane domains) to form 3 extracellular and 3 intracellular loops, as well as an intracellular C-terminus ${ }^{10}$ (Fig. 1). The loops of the receptor that transverse the lipid bilayer of the membrane comprise a cylindrical structure. The G-protein-coupled receptor regulates various effector proteins. ${ }^{12}$ Each $\mathrm{G}$ protein is a heterotrimer consisting of $\alpha, \beta$, and $\gamma$ subunits, and is classified by its distinctive $\alpha$ subunits. Among the various forms, the $\mathrm{G}_{\mathrm{s}}$ protein acts as a stimulatory protein of adenyl cyclase; $G_{i}$ and $G_{o}$, as inhibitory proteins of adenyl cyclase; and $\mathrm{G}_{\mathrm{q}}$ and $\mathrm{G}_{11}$ act to couple $\alpha$ receptors to phospholipase C. In the resting state, the $\mathrm{G}_{\mathrm{s}}$ protein is complexed with guanosine diphosphate. The activation of these receptors by catecholamines or agonists promotes the dissociation of guanosine diphosphate from the $\alpha$ subunit of the associated protein. This allows guanosine triphosphate (GTP) to bind to this G protein, and the $\alpha$ subunit dissociates from the $\beta$ unit. The activated GTP-bound $\alpha$ subunit acts to regulate the activity of its effector. When activated, the conversion of GDT to GTP occurs. GTP can then activate the adenyl cyclase enzyme, as well as activating cyclic guanosine monophosphate phosphodiesterase, phospholipase $\mathrm{C}$, and ion channels.

Receptor agonists bind to one or more of the transmembrane loops. The primary neurotransmitters at adrenergic receptors are norepinephrine and epinephrine. Adenyl cyclase stimulates conversion of adenosine triphosphate to cyclic adenosine monophosphate, which activates a protein kinase. The kinase phosphorylates a calcium channel, which promotes calcium influx and thus activates contractile proteins, increasing inotropic and chronotropic action in cardiac muscle. In bronchial smooth muscle, the increase in protein kinases and phosphorylation lead to bronchial smooth muscle relaxation because of decreased calcium influx and increased calcium uptake in the sarcoplasmic reticulum.

$\beta_{2}$ adrenergic receptors are also present in submucosal glands, endothelium of blood vessels, mast cells, and white 


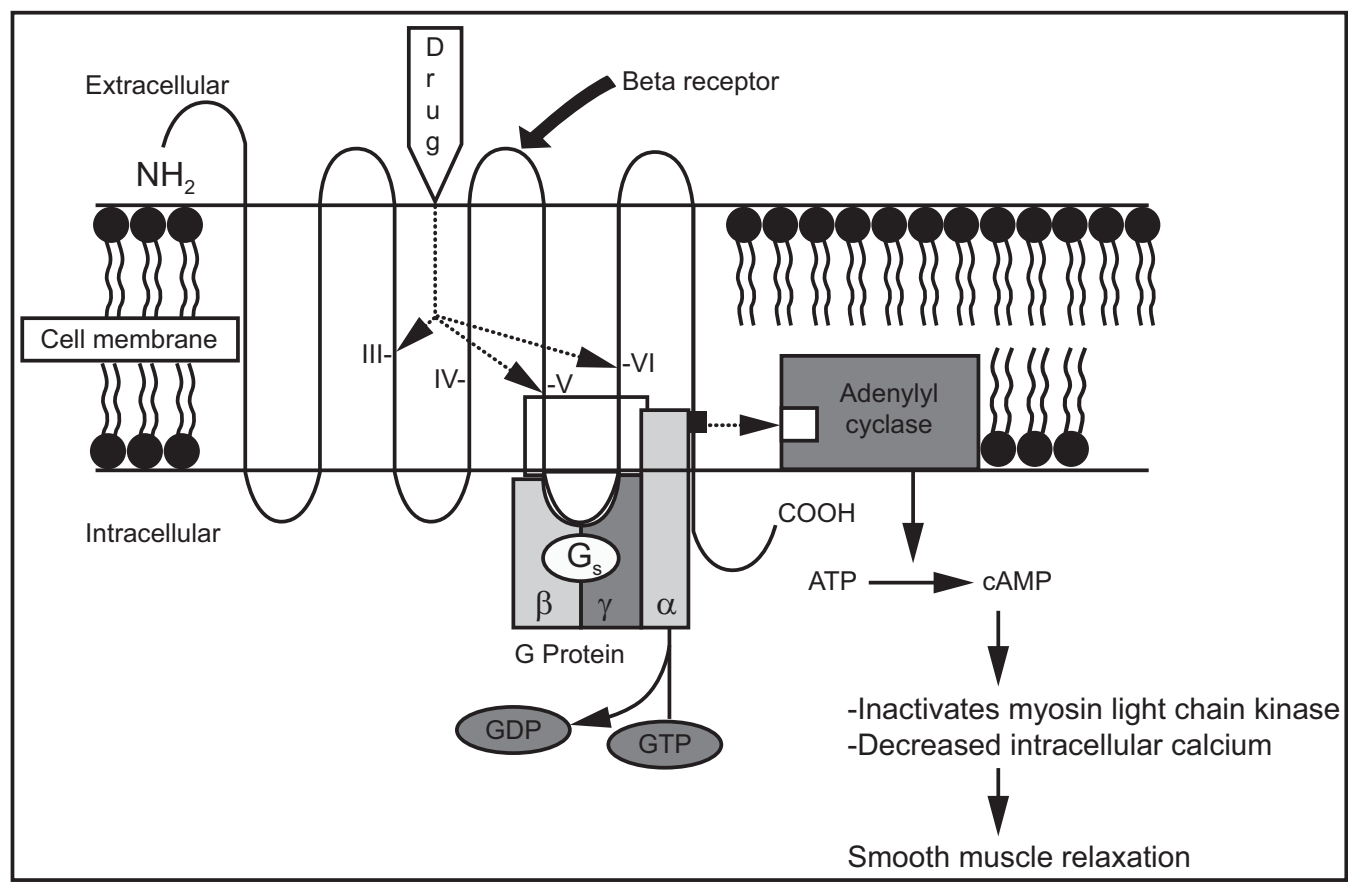

Fig. 1. Structure of $\beta$ adrenergic receptor. GDP = guanosine 5'; GTP = guanosine $5^{\prime}$-triphosphate; ATP = adenosine $5^{\prime}$-triphosphate; cAMP $=$ cyclic adenosine monophosphate. From Reference 11.

Table 2. Effects of Inhaled Beta Agonists in the Lung

Relaxes bronchial smooth muscle (bronchodilation)

Inhibits mast cell mediator release

Inhibits airway edema and plasma exudation

Increases mucociliary clearance

Increases mucus secretion

Decreases parasympathetic transmission

Reduces cough

blood cells involved in inflammatory responses, including eosinophils and lymphocytes. This explains the various effects beyond bronchodilation that are exhibited in vitro (Table 2). ${ }^{13}$

\section{Isomer Chemistry}

The carbons in the center of the phenylethylamine structure of $\beta$ adrenergic agents produce chirality, or asymmetry, of the compound. Depending on the position of the carbon (Fig. 2), the molecule appears as chiral mirror images that are not superimposable, like gloves for the right and left hand. These configurations, called enantiomers, rotate light in different directions, and thus are described as dextrorotary or levorotary, or as $\mathrm{S}$ enantiomers or $\mathrm{R}$ enantiomers, respectively, when described by their specific spatial configuration. From a chemical perspective, enantiomers exhibit similar properties. However, their interaction with the receptor can vary, resulting in different

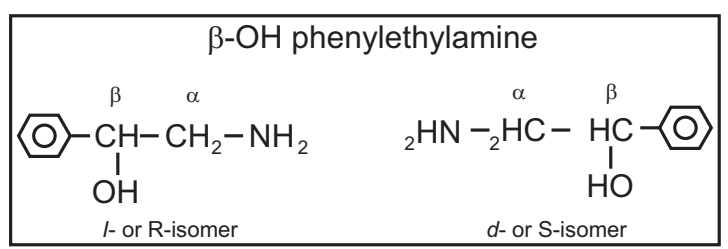

Fig. 2. Isomer chemistry showing the hydroxyl group on the $\beta$ carbon. From Reference 11.

actions and activities. In the case of epinephrine, the $\mathrm{R}$ isomer alone is responsible for activation of the $\beta$ adrenergic receptor and the resultant effects.

Albuterol, the most commonly used $\beta$ agonist therapy for relief of acute asthma, is a racemic mixture of the $R$ and $\mathrm{S}$ enantiomers. As is the case with epinephrine, the pharmacologic effects are due to the $\mathrm{R}$ isomer, whose affinity for the $\beta$-adrenergic receptor is 110 times greater than the $\mathrm{S}$ isomer. ${ }^{14}$ Whether the $\mathrm{S}$ isomer is inert or contributes to adverse effects through inhibition of the $R$ isomer is a controversy with no clear evidence of adverse effects shown in humans. High doses of $\beta$ agonists can lead to tachycardia, tremor, hypokalemia, and hyperglycemia. The pharmacodynamics of these drugs suggests that optimal bronchodilation is achieved far below dosages that can cause these adverse effects. It had been postulated that the single R enantiomer levalbuterol may cause less tachycardia and tremor based on studies in animals demonstrating that the $\mathrm{R}$ enantiomer appeared to be responsible for bronchodilation, while the $\mathrm{S}$ enantiomer with no bronchodilator effects could in- 
crease heart rate and tremor. In humans, the dose-related increase in heart rate and tremor are identical for racemic albuterol as for levalbuterol. ${ }^{14}$

\section{Selectivity and Specificity}

Agonists and antagonists of the $\beta$ receptor may exhibit receptor selectivity but not specificity. This suggests that some molecular configurations fit one subtype of a $\beta$ receptor better than other, but that off-target effects are possible, especially when higher or more frequent dosing is used. These effects also occur because most tissues express multiple subtypes of receptor; eg, cardiac muscle does not exclusively express $\beta_{1}$, and the bronchial smooth muscle does not express only $\beta_{2}$.

Improved selectivity for the $\beta_{2}$ receptor can be achieved by increasing the size of the molecule on the amine. ${ }^{7,15}$ Modifications to the aromatic ring can also prolong the duration of action; however, the more recent strategy used to develop long-acting and ultra long-acting therapies has been to elongate the ethylamine side chain of the structure.

\section{Pharmacodynamics and Pharmacokinetics of $\boldsymbol{\beta}_{2}$ Adrenergic Agonists}

As catecholamines, $\beta_{2}$ agonists exhibit low bioavailability, and the therapeutic benefit of oral administration is limited. These agents are absorbed in the gastrointestinal tract but undergo significant first-pass metabolism, which limits their true bioavailability. To overcome this, higher doses are required for oral therapy, which can result in unacceptable side effects.

Short-acting $\beta_{2}$ agonists (SABAs) have an onset of effect within minutes, which is the basis for their role as rescue treatment for acute symptoms associated with bronchospasm. The duration of effect of SABA therapy is $3-6 \mathrm{~h}$, which limits their role in chronic management. The first long-acting $\beta_{2}$ agonists (LABAs) exhibited prolonged bronchodilation, which allowed for 12-h dosing; now ultralong acting agents (ULABAs) have been developed that can be dosed every $24 \mathrm{~h}$ (Table 3). LABAs generally have greater specificity for the $\beta_{2}$ receptor compared to shortacting agents. The extended effectiveness of these agents is attributed to various factors, including the presence of large side chains on the molecular structure. In general, these side chains increase the lipophilicity of the molecule, which allows their retention in the lipid bilayer of the cell membrane. This is in contrast to albuterol, which is a more hydrophilic molecule that diffuses out of the membrane quickly.

LABAs differ in their pharmacologic properties, although the clinical relevance of these differences is unclear. For example, formoterol is more potent than salmeterol, which is a partial agonist at the receptor. Although
Table 3. Characteristics of Beta Agonist Medications

\begin{tabular}{|c|c|c|c|}
\hline Molecule & $\begin{array}{c}\text { Available } \\
\text { Inhalational } \\
\text { Routes (in the } \\
\text { United States) }\end{array}$ & $\begin{array}{l}\text { Lipophilicity } \\
\quad(\log P)\end{array}$ & $\begin{array}{l}\text { Duration of } \\
\text { Action/Dosing } \\
\text { Frequency }\end{array}$ \\
\hline Albuterol & pMDI, DPI, nebulizer & 1.4 & $4-6 \mathrm{~h}$ \\
\hline Arformoterol & Nebulizer & 2.2 & $12 \mathrm{~h}$ \\
\hline Formoterol & pMDI, nebulizer & 2.2 & $12 \mathrm{~h}$ \\
\hline Levalbuterol & pMDI, nebulizer & 1.4 & $4-6 \mathrm{~h}$ \\
\hline Indacaterol & DPI & 3.9 & $24 \mathrm{~h}$ \\
\hline Olodaterol & Soft mist inhaler & NA & $24 \mathrm{~h}$ \\
\hline Salmeterol & DPI & 4.2 & $12 \mathrm{~h}$ \\
\hline Vilanterol & DPI & 3.8 & $24 \mathrm{~h}$ \\
\hline \multicolumn{4}{|c|}{$\begin{array}{l}\text { Data from Reference } 16 . \\
\text { Log } P \text { describes the partition between lipid and aqueous phases, thus higher lipophilicity is } \\
\text { indicated by larger number. } \\
\text { pMDI = pressurized metered-dose inhaler } \\
\text { DPI = dry powder inhaler } \\
\text { NA = not applicable }\end{array}$} \\
\hline
\end{tabular}

formoterol is less lipophilic than salmeterol, it attaches to the $\beta$ receptor more quickly and its onset is more rapid than salmeterol. On the other hand, a partial agonist is expected to produce less desensitization and fewer $\beta$ adrenergic-associated side effects. Despite the differences in these 2 agents, clinical efficacy and safety appear to be similar. The drugs also differ in intrinsic activity and selectivity at the $\beta_{2}$ receptor, although the clinical importance of these differences is unproven. ${ }^{17}$ Indacaterol was the first cleared ULABA with a 24-h duration of action, which allows for once-daily administration. Other new agents, including olodaterol and vilanterol, are single enantiomer products that exert full agonist activity sustained for $24 \mathrm{~h}$.

\section{Desensitization and Tolerance}

With chronic stimulation by $\beta_{2}$ agonists, adrenergic receptors have decreased intensity of response and duration of effect, known as tolerance. Tolerance is exhibited with both SABAs and LABAs, and it is characterized more by a loss of bronchoprotective effect rather than the bronchodilator effect. The activity of adrenergic receptors are influenced by several factors, including hormones, catecholamines, and medications. Changes in the number and function of receptors on the cell surface will change the magnitude and duration of response. ${ }^{12}$ These changes can be clinically relevant as they may limit the therapeutic response to treatment with prolonged high-dose administration, while adverse effects such as tachycardia and hypokalemia are not generally susceptible to receptor tolerance. Desensitization can be homologous or heterologous. Homologous desensitization occurs directly at a receptor activated by an agonist, whereas a heterologous change 
refers to another receptor in the same region but is not directly involved in agonist activation.

Several mechanisms contribute to receptor desensitization, including changes in protein transcription or translation that develop over several days, while desensitization due to phosphorylation of amino acids, or changes in receptor cellular location, can occur in hours. Prolonged phosphorylation of the receptor through activity of protein kinases as a result of repeated or prolonged use leads to internalization of the receptor. Once phosphorylated, the receptor has an increased affinity for arrestins, which attenuates the ability to activate $G$ proteins due to steric hindrance. Arrestin then interacts with clathrin, leading to endocytosis of the receptor. The development of tolerance to $\beta_{2}$ agonists can be attenuated by corticosteroid therapy.

\section{Adverse and Off-Target Effects}

The primary and clinically relevant effect of inhaled $\beta_{2}$ agonists is bronchodilation. ${ }^{12}$ However, in vitro studies suggest that $\beta$ agonists may have nonbronchodilator effects, such as decreasing production and activity of leukotrienes and histamine from mast cells, reducing microvascular permeability, inhibiting phospholipases A2, and increasing ciliary beat frequency (Table 2). The anti-inflammatory effects are thought to be due to functional antagonism by inhibiting smooth muscle contraction, rather than direct anti-inflammatory effects. Although $\beta$ agonists appear to reduce some aspects of inflammation in vitro, there are data suggesting that the chronic use of $\beta$ agonist bronchodilators may be pro-inflammatory, which may be one of the reasons that chronic use of inhaled $\beta$ agonists perpetuates asthmatic airway inflammation. These observations remain speculative.

Off-target effects can present as side effects or adverse drug reactions, and they occur due to $\beta_{2}$ receptor stimulation of cardiac and peripheral muscle, or $\beta_{1}$ adrenergic effects. At the $\beta_{2}$ receptor, similar events occur with stimulation and result in activation of protein kinase. In this instance, protein kinase promotes calcium influx and activates contractile proteins. Protein kinase also phosphorylates troponin and $\mathrm{G}^{*}$, which activates a calcium channel resulting in positive inotropy and chronotropy in cardiac tissue and blood vessel vasodilation.

Albuterol has been reported to help clear pulmonary edema fluid from the alveolus by accelerating the resorption of alveolar fluid. This effect has been demonstrated in patients with fluid overload of cardiogenic pulmonary edema; however, the clinical implications are modest. ${ }^{18}$ It has also been suggested that the inhalation of a $\beta$ agonist bronchodilator will improve the effectiveness of airway clearance maneuvers, and so albuterol is often inhaled before chest physical therapy or airway clearance maneuvers. Beneficial effects on mucociliary clearance have been demonstrated in
COPD. ${ }^{19}$ There are no data demonstrating that this improves mucus clearance in individuals with asthma. ${ }^{20}$

Adverse or unwanted effects can occur due to excessive receptor activation or actions at off-target sites. Off-target effects are reduced with the use of the inhaled route as well as more selective therapies, but they are not eliminated. Commonly observed side effects or adverse reactions are summarized in Table 3. Fortunately, tolerance to these effects usually develops with regular use.

$\beta_{2}$ agonists have been associated with an increased risk of adverse cardiovascular events due to actions at the $\beta_{1}$ receptor. All $\beta_{2}$ agonists can cause tachycardia and palpitations. ${ }^{21}$ Activation can increase the risk of arrhythmias, especially in patients with underlying cardiovascular disease. Data regarding risk are conflicting, but caution is advised when using these agents in patients with preexisting cardiovascular disease..$^{22}$

Tal et $\mathrm{al}^{23}$ were among the first to report that the administration of $\beta$ agonists could acutely worsen hypoxemia in children with asthma. The presumed mechanism was vasodilatation with improvement of perfusion to underventilated portions of the lung, leading to an increased mismatch of ventilation and perfusion. It is recommended patients who are hypoxemic and are receiving a $\beta$ agonist should also receive supplemental oxygen to minimize this risk.

Investigators in the 1980s showed that the inhalation of $\beta$ agonists worsened air flow in infants with tracheomalacia. It was postulated that, with poor cartilage development, airway patency was being maintained by intrinsic airway muscle tone, and that the administration of a $\beta$ agonist would lead to bronchial relaxation and worsening of the airway malacia. They further showed that the administration of bethanechol, a cholinergic agent, improved air flow. ${ }^{24}$ Many children who have airway malacia also have wheeze, which can be confused for asthma. For these reasons, it is recommended that neonates or infants with tracheomalacia not receive bronchodilators.

\section{Drug Interactions}

Although the inhaled route of administration can dramatically reduce side effects, there are pharmacokinetic drug interaction considerations with some $\beta$ agonists. Salmeterol is metabolized by cytochrome (CYP) p450 3A4, and formoterol is a substrate for several CYP enzymes, including 2D6, 2C9, and 2C19. The product labeling for salmeterol suggests caution when using with strong $3 \mathrm{~A} 4$ inhibitors, including ritonavir or ketoconazole, because of the increased risk for adverse effects from higher salmeterol concentrations. The product label for formoterol does not mention CYP-related drug interactions, but there is a statement cautioning use with other agents that can prolonged the QT interval of cardiac rhythm. 


\section{Safety of Inhaled $\boldsymbol{\beta}_{2}$ Agonists}

The clinical safety of inhaled $\beta_{2}$ agonists has been a source of controversy for decades. In the 1990s, an increased risk for asthma deaths was attributed to SABA use, including albuterol. In 2006, the post-marketing SMART study ${ }^{25}$ reported an increased risk of fatal or nearfatal asthma associated with salmeterol compared to usual therapy. These data, along with additional small studies and a meta-analysis, resulted in an FDA black box warning in 2010 that is included on all products containing a LABA in the United States. The FDA also required manufacturers of LABA-containing products to conduct safety studies. The results of those long-term studies are now published and support the safety of LABA therapy when used in combination with inhaled corticosteroids in children, adolescents, and adults. ${ }^{26-28}$ In November 2017, the FDA removed the black box warning from products containing a combination of a LABA and inhaled corticosteroid.

\section{Cholinergic (Muscarinic) Receptors}

\section{History}

Anticholinergics agents include naturally occurring belladonna alkaloids (atropine, scopolamine). For centuries, Ayurvedic healers in India burned leaves from Datura species (jimson weed, thorn apple, moonflowers) and inhaled the vapors for relief of asthma. This practice was brought to England by General Gent, ${ }^{29}$ and cigarettes containing Datura alkaloids were sold as asthma therapy as late as the 1970s. These alkaloid compounds have been modified to create synthetic derivatives with improved clinical applications, including inhaled ipratropium and tiotropium, which are quaternary ammonium compounds with limited systemic absorption and blood-brain barrier translocation. In clinical studies, the other anticholinergic effects of these inhaled therapies are not significant, including effects on sputum volume or viscosity.

Ipratropium was the first commercially available inhaled anticholinergic agent, cleared in $1987 . .^{30}$ It is short-acting and nonselective in that it blocks all 3 muscarinic receptors $\left(\mathrm{M}_{1}, \mathrm{M}_{2}, \mathrm{M}_{3}\right)$. Tiotropium, a long-acting agent, selectively blocks $M_{1}$ and $M_{3}$ receptors. Antagonism at the $M_{3}$ receptor appears to be the most clinically relevant for bronchodilation $^{31}$ and for decreasing mucin hypersecretion driven by neutrophil elastase. ${ }^{32}$ Other long-acting agents that are now available are selective for the $\mathrm{M}_{3}$ receptor as well.

\section{Structure and Function}

A report published in 1914 described choline ester responses that were similar to nicotine or muscarine, de- pending on the preparation. ${ }^{33}$ Nicotinic receptors are located mainly on autonomic ganglia and skeletal muscle. These receptors are ligand-gated ion channels, and activation results in an increase in permeability to sodium and calcium, leading to depolarization and excitation. ${ }^{34}$ Muscarinic receptors are G-protein-coupled receptors, and they are found in the central nervous system and the periphery on autonomic effector cells innervated by postganglionic parasympathetic nerves, including smooth and cardiac muscle. ${ }^{31}$

$\mathrm{ACH}$ is the primary neurotransmitter at receptors throughout the body, and it activates both nicotinic and muscarinic receptors. ACH is an excitatory neurotransmitter that requires an energy-dependent pump for uptake into the synaptic vesicle, where it is stored in the neuron. During neurotransmission, $\mathrm{ACH}$ is released into the synaptic cleft. ${ }^{35}$ The enzyme acetylcholinesterase is also found at the postsynaptic membrane and inactivates $\mathrm{ACH}$ through hydrolysis. Choline liberated by hydrolysis is taken up again by the nerve, and new $\mathrm{ACH}$ is synthesized and stored (Fig. 3).

Nicotinic receptor antagonists are used clinically as anesthetics, skeletal muscle relaxants, and central and adrenal-active therapies. Muscarinic receptor antagonists are more relevant for this review as they are present on airway smooth muscle. In clinical practice, the terms anticholinergic and antimuscarinic are often used interchangeably, although in the airway the action occurs at the muscarinic receptor. Parasympathetic innervation of airway smooth muscle is provided by the tenth cranial nerve, the vagus.

Antagonists of muscarinic receptors exhibit both orthosteric binding at the active site and allosteric binding elsewhere, which changes the conformation of the proteinbinding site. There are 5 subtypes of muscarinic receptors, and 3 of them, $\mathrm{M}_{1}-\mathrm{M}_{3}$, are located on airway smooth muscle, on the nerves that control smooth muscle, and on glands. Muscarinic receptors control basal airway smooth muscle tone, which is increased in COPD. ${ }^{36} \mathrm{M}_{1}$ and $\mathrm{M}_{3}$ are excitatory and promote $\mathrm{ACH}$ release and coupling through $\mathrm{G}_{\mathrm{q}} / \mathrm{G}_{11}$ to activate phospholipase $\mathrm{C}$, which results in phosphatidylinositol turnover. Calcium is released, resulting in an increase in intracellular calcium and receptor activation. $\mathrm{M}_{2}$ receptors inhibit adenylyl cyclase activity through another G-protein $\left(\mathrm{G}_{\mathrm{i}} / \mathrm{G}_{\mathrm{o}}\right)$, which results in prolonged opening of ion channels and flow of calcium and potassium. Activation of potassium channels leads to hyperpolarization of the cell membrane. In addition, $\mathrm{ACH}$ activation of $\mathrm{M}_{2}$ receptors reduces $\mathrm{ACH}$ release from the vesicle. The summative effect of muscarinic receptor antagonists is decreased airway tone with improvement in expiratory air flow. ${ }^{37}$

$\mathrm{M}_{3}$ receptors appear to be most clinically important in mediating smooth muscle contraction. This is also true in bladder smooth muscle, which may partially explain the 


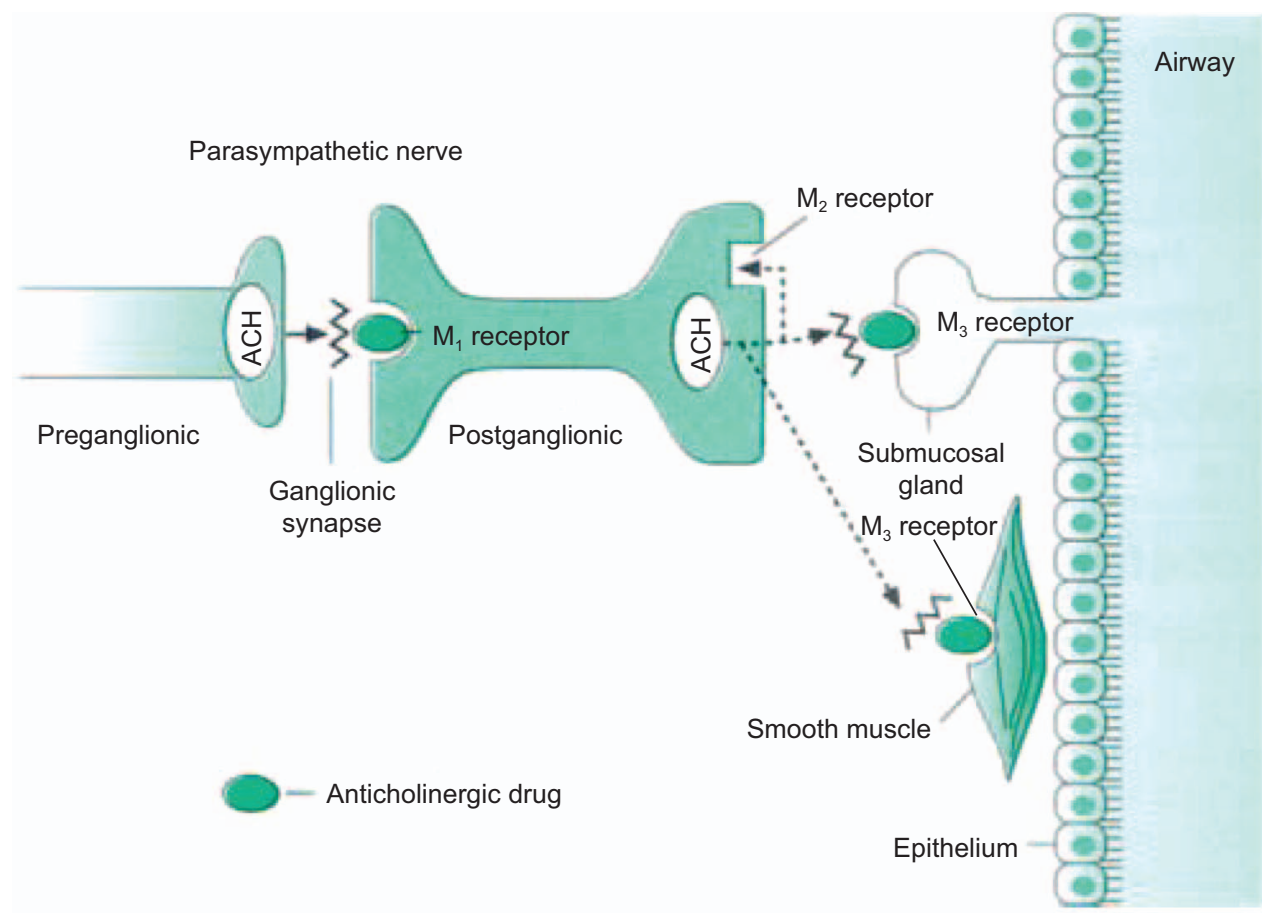

Fig. 3. Identification and location of muscarinic receptor subtypes $M_{1}, M_{2}$, and $M_{3}$ in the vagal nerve, submucosal gland, and bronchial smooth muscle in the airway, showing nonspecific blockade by anticholinergic drugs. $\mathrm{ACH}=$ acetylcholine. From Reference 30 , with permission.

potential side effect of urinary retention. ${ }^{38}$ The structure of the $\mathrm{M}_{3}$ receptor has intracellular and extracellular loops and a large extracellular vestibule within a hydrophilic channel, which is where the orthosteric binding site resides (eg, for tiotropium). Studies show that selective antagonists (eg, tiotropium) bind to $\mathrm{M}_{2}$ receptors as well as $\mathrm{M}_{3}$ receptors, but they dissociate from $\mathrm{M}_{3}$ receptors much more slowly. ${ }^{38}$

\section{Pharmacodynamics and Pharmacokinetics}

Bronchodilation from ipratropium is evident in $15 \mathrm{~min}$, with a maximum effect at $1.5 \mathrm{~h}$. Receptor binding is estimated at $3 \mathrm{~h}$, and the duration of effect lasts for up to $6 \mathrm{~h}$. Serum concentrations are undetectable with usual doses. The duration of bronchodilation from short-acting inhaled anticholinergics is longer compared to SABAs, and tolerance does not appear to occur in response to the anticholinergic effects.

Tiotropium was developed as a structural analogue of glycopyrrolate. This agent binds the $\mathrm{M}_{3}$ receptor for $36 \mathrm{~h}$, and bronchodilation persists for $24 \mathrm{~h}$. After inhalation of tiotropium as a dry powder, about $14 \%$ of the drug appears in the urine. Newer long-acting muscarinic antagonist (LAMA) therapies (eg, aclidinium, glycopyrrolate, and umeclidinium) exhibit a faster onset of action compared to tiotropium, although the clinical relevance is unclear be- cause the main benefit of these therapies is a prolonged duration of effect (Table 4). In late 2017, glycopyrrolate was cleared as the first nebulized formulation of a LAMA therapy.

\section{Adverse and Off-Target Effects}

The most common side effects from inhaled anticholinergics is dry mouth and, with aerosol administration using a poorly fitting mask, mydriasis. These agents have no adverse effects on mucus clearance or viscosity. ${ }^{39}$ Inhaled anticholinergics have negligible effects on heart rate and blood pressure (Table 5). Some observational studies have implicated that inhaled anticholinergic therapies relate to an increased risk of stroke and myocardial infarction. ${ }^{40}$ The basis for this increased risk is unclear, but it may be due to the anticholinergic effect on cardiac muscle. Findings in observational studies differ from those of randomized clinical trials; however, as with precautions for $\beta_{2}$ agonists, caution is prudent when initiating therapy in patients with preexisting cardiovascular disease.

\section{Drug Interactions}

Inhaled anticholinergic therapies rarely cause side effects related to the blockage of cholinergic receptors. The 


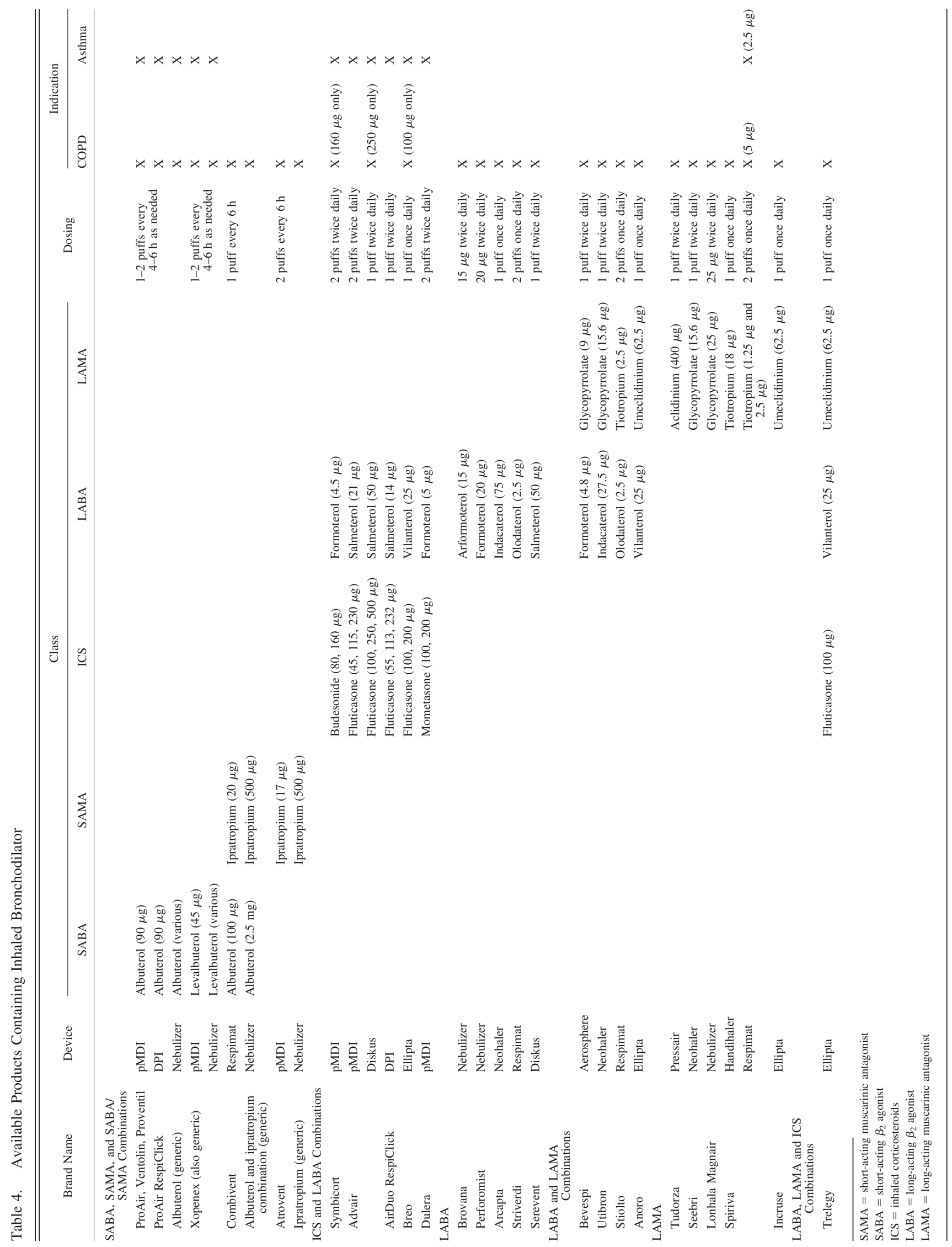


Table 5. Possible Adverse Effects Reported for Inhaled Anticholinergics

\begin{tabular}{ll}
\hline \hline Organ System & \multicolumn{1}{c}{ Observed Adverse Effect } \\
\hline Otolaryngology & Dry mouth, blurred vision, taste disturbances \\
Genitourinary & Urinary retention \\
Gastrointestinal & Constipation \\
Cardiovascular & Tachycardia (rare) \\
\hline
\end{tabular}

quaternary structure also limits central nervous system penetration and avoids the side effects, including delirium, associated with atropine. As a result, there are no clinically relevant drug interactions associated with these therapies.

\section{Therapeutic Administration of Bronchodilator Medications}

The $\beta$ agonist and the anticholinergic bronchodilator medications are effective when administered systemically by mouth or intravenously, or when delivered topically as an aerosol deposited on the airway. Inhalational therapy is generally preferred. Systemic administration requires a higher dosage with greater systemic side effects and no therapeutic advantage. ${ }^{41}$ This is true even for the critically ill patient. Both anticholinergics and $\beta$ agonists have an extremely broad therapeutic window when given by aerosol.

Aerosols can be delivered as wet aerosols via traditional Venturi nebulizers, vibrating mesh nebulizers, dry powder inhalers (DPI), slow mist inhalers, or pressurized metereddose inhalers (pMDI). Under most circumstances, the use of either a DPI or a pMDI is preferred to nebulization. ${ }^{42}$ Nebulizers used for aerosol administration vary greatly in their respirable mass output, or the amount of particles in the aerosol of the appropriate size for inhalation. Furthermore, nebulization is generally a longer and more complex procedure than using a pMDI or DPI. Nebulization entails measuring the medication into the nebulizer cup, having the patient breathe consistently and deeply during the period of nebulization (generally about $5 \mathrm{~min}$ ), and then cleaning the nebulizer before it is put away. For these reasons nebulization has the lowest adherence rate of any form of aerosol medication delivery. ${ }^{43}$

The pMDI has been a standard for aerosol delivery for $>50 \mathrm{y}$. Recent changes from the chlorofluorocarbon (CFC-9 and CFC-11) carrier to a more environmentally friendly hydrofluoroalkane (HFA-134a) carrier, in response to the Montreal protocol to protect the ozone layer, does not lead to a change in either aerosol size or output from the pMDI. Because aerosols from the pMDI are delivered at a high velocity and require significant coordination between actuation and inhalation, it is recommended that these be used either with a spacer or with a valved holding chamber that allows the aerosol cloud to mature (ie, larger particles are removed) and thus reduces oropharyngeal deposition, swallowing, and systemic side effects. Many studies have shown that, when used appropriately, medication delivered by either pMDI or DPI is equivalent or superior to that delivered by jet nebulization, often at a lower dose. DPIs are generally breath-activated and therefore can be ideal for delivery of medication to the older child and adult. They do require significant inspiratory flow to disaggregate the particles, although active-dispersal DPIs have been developed. In all cases, whether using a nebulizer, a pMDI, a holding chamber, or DPI, dosages should never be adjusted based on the patient's age or weight. For any child old enough (generally 3 y and older), the use of a mouthpiece will effectively double the amount of medication delivered to the airways compared to the same number of inhalations delivered using a masked interface. ${ }^{42}$

Regardless of the device chosen for aerosol delivery, education and appropriate use is important to ensure successful outcomes. It is recommended that patients bring their aerosol device to clinic at each visit and demonstrate appropriate use. In that sense, it does not matter how effective the medication is because it will not work if it is not inhaled using appropriate technique as prescribed. ${ }^{44}$

\section{Bronchodilator Therapy for Airway Diseases}

\section{Asthma}

The benefits of using $\beta$ agonist bronchodilators to relieve smooth muscle spasm are well established as a hallmark of therapy for acute asthma. However, the chronic use of $\beta$ agonists is thought to worsen asthma control. This may be due to decrease in $\beta$ receptor expression on the target cells, a decreased rate of adherence to inhaled corticosteroids and other controller medications, and the possibility that chronic $\beta$ agonist use might worsen inflammation.

When the LABA salmeterol was introduced, a large study evaluating its use as monotherapy for chronic asthma (the SMART study) showed excess mortality leading to an FDA black box warning about the use of this medication alone. ${ }^{25}$ Because this excess mortality was primarily noted among African-American subjects, and this group has a greater prevalence of homozygous Arg/Arg polymorphism at locus 16 of the $\beta$ agonist receptor (the normal receptor type is Arg/Gly), this Arg/Arg polymorphism was thought to lead to an ineffective response to inhaled bronchodilators. Reanalysis of the data and a subsequent study (BARGE) ${ }^{45}$ have failed to confirm this, and it is now thought that this excess of death in patients receiving salmeterol monotherapy was primarily due to inadequate use of inhaled corticosteroids rather than due to the drug itself. 
The duration of action of inhaled albuterol is $4-6 \mathrm{~h}$. Nevertheless, it is common practice to give large amounts of albuterol over a fairly short period of time when treating acute asthma. While administering albuterol every $1-2 \mathrm{~h}$ for the first $12 \mathrm{~h}$ may be effective therapy, particularly in airways that are obstructed, once the airway $\beta$ receptors are saturated, more frequent use of these drugs adds little benefit while increasing adverse effects. A large prospective trial ${ }^{46}$ did not demonstrate clinical worsening of asthma when albuterol was dosed at regular intervals was compared to albuterol administration as needed. In another study ${ }^{47}$ in adults with asthma exacerbations, the as-needed administration of albuterol was as effective as regularly scheduled administration of this drug, but the former strategy led to a shorter length of hospital stay and a lower total dose of $\beta$ agonist used.

\section{COPD}

Bronchodilator use is common in patients with COPD, although the response is variable. Those patients who demonstrate elements of fixed air-flow obstruction and reversible air-flow obstruction with triggering factors may have the asthma-COPD overlap syndrome. ${ }^{48}$ It is likely that these patients will be more responsive to bronchodilators than those with so-called pure COPD. Nonetheless, one study demonstrated that $>50 \%$ of COPD subjects (without an asthma component) demonstrated a significant bronchodilator response on spirometry. ${ }^{49}$

\section{Bronchiolitis}

For many years, it was assumed that bronchiolitis was an infantile form of asthma, and thus the use of a $\beta$ agonist bronchodilator was routinely recommended. Accumulating evidence demonstrating a clear lack of effectiveness of inhaled $\beta$ agonists in the treatment of this disease has finally led to consensus among published guidelines that there is no value to administering albuterol to infants with bronchiolitis; in addition, because of the known side effects of this medication, it should not be administered to infants with bronchiolitis. ${ }^{50}$ There is also no role for the use of inhaled albuterol in premature newborns with respiratory distress syndrome of the newborn. With increased drug absorption from the newborn lung, this poses a risk of systemic adverse effects.

\section{Cystic Fibrosis}

There is controversy related to the effectiveness of $\beta$ agonist bronchodilators in patients with cystic fibrosis $(\mathrm{CF})$. Guidelines from the Cystic Fibrosis Foundation recommend the use of albuterol before administering chest physical therapy or mucoactive medications, although it has not been clearly demonstrated that this improves airway clearance. ${ }^{51}$ Patients with $\mathrm{CF}$ more frequently have bronchial hyper-responsiveness than those who do not have $\mathrm{CF}$, but bronchial hyper-responsiveness is variable and is not always responsive to inhaled bronchodilators. It is also unclear if there is increased bronchial hyper-responsiveness during a $\mathrm{CF}$ exacerbation of pulmonary disease, which is when these drugs are often administered. The one documented benefit of inhaled albuterol in $\mathrm{CF}$ is use before administration of an osmotic agent, such as hypertonic saline or mannitol, which can produce bronchospasm in a subset of patients with underlying airway hyper-responsiveness.

\section{Research and Development of Bronchodilators}

The choices among long-acting inhaled $\beta_{2}$ agonists and anticholinergic therapies have improved in recent years. Currently, there are a variety of products and inhalational forms for these products. Newer combination inhalers, containing both a LABA and a LAMA, also represent a significant advance for treatment of COPD. The newest agents include bifunctional molecules that exhibit both muscarinic antagonism and $\beta_{2}$ agonism. These agents are referred to as MABAs or LAMA/LABAs. One challenge in the development of these agents is determining the optimal ratio of each activity in the therapeutic entity. Nonetheless, with the development of new medications and new aerosol devices, the key to optimizing outcomes from therapy is identifying the right drug and delivery device, for the right patient, at the right time. ${ }^{52}$

\section{Summary}

Adrenergic and cholinergic and receptors are major targets for bronchodilator therapy. Expanding knowledge of receptor subtypes and G-protein signaling, agonist and antagonist specificity, and drug delivery have led to the introduction of safer medications with fewer adverse effects, medications with longer duration of action, and more effective and efficient aerosol delivery devices. There are a variety of products and inhalational forms for these bronchodilators. Combination inhalers, containing a LABA and a LAMA, are a significant advance for treatment of COPD.

\section{REFERENCES}

1. Cazzola M, Page C, Matera MG. Long-acting muscarinic receptor antagonists for the treatment of respiratory disease. Pulm Pharmacol Ther 2013;26(3):307-317.

2. Greenblatt DJ, Shader RI. Drug therapy. Anticholinergics. N Engl J Med 1973;288(23):1215-1219.

3. Chen KK, Schmidt CF. The action and clinical use of ephedrinean alkaloid isolated from the Chinese drug, ma huang. J Am Med Assoc 1926;87(11):836-842.

4. Kahn R. Zur physiologie der trachea. Arch Physiol 1907;398-426. 


\section{BRONCHODILATOR MEDiCATIONS}

5. Bullowa JGM, Kaplan DM. On the hyperdermatic use of adrenalin chloride in the treatment of asthmatic attacks. Med News 1903;83: 787.

6. Barger G, Dale HH. Chemical structure and sympathomimetic action of amines. J Physiol 1910;41:19.

7. Leifer KN, Wittig HJ. The beta-2 sympathomimetic aerosols in the treatment of asthma. Ann Allergy 1975;35(2):69-80.

8. Ahlquist RP. A study of the adrenotropic receptors. Am J Physiol 1948;153:586-600.

9. Lands AM, Arnold A, McAuliff JP, Luduena FP, Brown TG Jr. Differentiation of receptor systems activated by sympathomimetic amines. Nature (London) 1967;214:597-598.

10. Fraser CM, Venter JC. Beta-adrenergic receptors. Relationship of primary structure, receptor function, and regulation. Am Rev Respir Dis 1990;141(2 Pt 2):S22-S30.

11. Rau J. Inhaled adrenergic bronchodilators: historical development and clinical application. Respir Care 2000;45(7):854-863.

12. Billington CK, Penn RB, Hall IP. B2 agonists. Handb Exp Pharmacol 2017;237:23-40.

13. Bateman ED, Rennard S, Barnes PJ, Dicpinigaitis PV, Gosens R, Gross NJ, Nadel JA, et al. Alternative mechanisms for tiotropium. Pulm Pharmacol Ther 2009;22(6):533-542.

14. Jat KR, Khairwa A. Levalbuterol versus albuterol for acute asthma: a systematic review and meta-analysis. Pulm Pharmacol Ther 2013; 26(2):239-248.

15. Brittain RT, Jack D, Ritchie AC. Recent beta-adrenoceptor stimulants. Adv Drug Res 1970;5:197-253.

16. Antus B. Pharmacotherapy of chronic obstructive pulmonary disease: a clinical review. ISRN Pulmonology 2013;2013:1-11.

17. Woo AY, Song Y, Zhu W, Xiao RP. Advances in receptor conformation research: the quest for functionally selective conformations focusing on the $\beta 2$-adrenoceptor. Br J Pharmacol 2015;172(23): $5477-5488$

18. Mutlu GM, Koch WJ, Factor P. Alveolar epithelial beta 2-adrenergic receptors: their role in regulation of alveolar active sodium transport. Am J Respir Crit Care Med 2004;170(12):1270-1275.

19. Bennett WD, Almond MA, Zeman KL, Johnson JG, Donohue JF. Effect of salmeterol on mucociliary and cough clearance in chronic bronchitis. Pulmon Pharmacol Ther 2006;19:96-100.

20. Daviskas E, Anderson SD, Shaw J, Eberl S, Seale JP, Yang IA, Young IH. Mucociliary clearance in patients with chronic asthma: effects of beta agonists. Respirology 2005;10(4):426-435.

21. Cazzola M, Page CP, Rogliani P, Matera MG. $\beta 2$-agonist therapy in lung disease. Am J Respir Crit Care Med 2013;187(7):690-696.

22. Maak CA, Tabas JA, McClintock DE. Should acute treatment with inhaled beta agonists be withheld from patients with dyspnea who may have heart failure? J Emerg Med 2011;40(2):135-145.

23. Tal A, Pasterkamp H, Leahy F. Arterial oxygen desaturation following salbutamol inhalation in acute asthma. Chest 1984;86(6):868869

24. Panitch HB, Keklikian EN, Motley RA, Wolfson MR, Schidlow DV. Effect of altering smooth muscle tone on maximal expiratory flows in patients with tracheomalacia. Pediatr Pulmonol 1990;9(3):170 176.

25. Nelson HS, Weiss ST, Bleecker ER, Yancey SW, Dorinsky PM; SMART Study Group. The Salmeterol Multicenter Asthma Research Trial: a comparison of usual pharmacotherapy for asthma or usual pharmacotherapy plus salmeterol. Chest. 2006;129(1):15-26.

26. Chauhan BF, Chartrand C, Ni Chroinin M, Milan SJ, Ducharme FM. Addition of long-acting beta2-agonists to inhaled corticosteroids for chronic asthma in children. Cochrane Database Syst Rev 2015;(11): CD0079.
27. Stempel DA, Raphiou IH, Kral KM, Yeakey AM, Emmett AH, Prazma CM, Buaron KS, Pascoe SJ; AUSTRI Investigators. Serious asthma events with fluticasone plus salmeterol versus fluticasone alone. N Engl J Med 2016;374(19):1822-1830.

28. Wechsler ME, Kunselman SJ, Chinchilli VM, Bleecker E, Boushey HA, Calhoun WJ, et al.; National Heart, Lung and Blood Institute's Asthma Clinical Research Network. Effect of beta2-adrenergic receptor polymorphism on response to long acting beta2 agonist in asthma (LARGE trial): a genotype-stratified, randomised, placebocontrolled, crossover trial. Lancet 2009;374(9703):1754-1764.

29. Jackson M. "Divine stramonium": the rise and fall of smoking for asthma. Med Hist 2010;54(2):171-194.

30. Rau JL. Design principles of liquid nebulization devices currently in use. Respir Care 2002;47(11):1257-1275.

31. Alagha K, Palot A, Sofalvi T, Pahus L, Gouitaa M, Tummino C, Martinez S, et al. Long-acting muscarinic receptor antagonists for the treatment of chronic airway diseases. Ther Adv Chronic Dis 2014;5(2):85-98.

32. Komiya K, Kawano S, Suzaki I, Akaba T, Kadota J, Rubin BK. Tiotropium inhibits mucin production stimulated by neutrophil elastase but not by IL-13. Pulm Pharm Therap 2018;48:161-167.

33. Dale HH. The action of certain esters and ethers of choline, and their relation to muscarine. J Pharmacol Exp Ther 1914;6:147-190.

34. Walker JK, Gainetdinov RR, Feldman DS, McFawn PK, Caron MG, Lefkowitz RJ, et al. G protein-coupled receptor kinase 5 regulates airway responses induced by muscarinic receptor activation. Am J Physiol Lung Cell Mol Physiol 2004;286(2):L312-L319.

35. Fagerlund MJ, Eriksson LI. Current concepts in neuromuscular transmission. Br J Anaesth 2009;103(1):108-114

36. Fryer AD, Jacoby DB. Muscarinic receptors and control of airway smooth muscle. Am J Respir Crit Care Med 1998;158(5 Pt 3):S154S160

37. Ferrando M, Bagnasco D, Braido F, et al. Umeclidinium for the treatment of uncontrolled asthma. Expert Opin Invest Drugs 2017; 26(6):761-766.

38. Kruse AC1, Li J, Hu J, Kobilka BK, Wess J. Novel insights into M3 muscarinic acetylcholine receptor physiology and structure. J Mol Neurosci 2014;53(3):316-323.

39. Kishioka C, Cheng PW, Seftor RE, Lartey PA, Rubin BK. Regulation of mucin secretion in the ferret trachea. Otolaryngol Head Neck Surg 1997;117(5):480-486.

40. Suissa S, Dell'Aniello S, Ernst P. Concurrent use of long-acting bronchodilators in COPD and the risk of adverse cardiovascular events. Eur Respir J 2017;49(5):1602245.

41. Rubin BK. Air and soul: the science and application of aerosol therapy. Respir Care 2010;55(7):911-921.

42. Rubin BK, Fink JB. Optimizing aerosol delivery by pressurized metered-dose inhalers. Respir Care 2005;50(9):1191-1200.

43. Rubin BK. What does it mean when a patient says, "my asthma medication is not working?" Chest 2004;126(3):972-981.

44. Fink JB, Rubin BK. Problems with inhaler use: a call for improved clinician and patient education. Respir Care 2005;50(10):1360-1374.

45. Israel E, Chinchilli VM, Ford JG, Boushey HA, Cherniack R, Craig $\mathrm{TJ}$, et al. Use of regularly scheduled albuterol treatment in asthma: genotype-stratified, randomised, placebo-controlled cross-over trial. Lancet 2004;364(9444):1505-1512.

46. Drazen JM, Israel E, Boushey HA, Chinchilli VM, Fahy JV, Fish JE, et al. Comparison of regularly scheduled with as-needed use of albuterol in mild asthma. Asthma Clinical Research Network. N Engl J Med 1996;335(12):841-847. 
47. Chandra A, Shim C, Cohen HW, Chung V, Maggiore D, Mani K, Dhuper S. Regular vs ad-lib albuterol for patients hospitalized with acute asthma. Chest 2005;128(3):1115-1120.

48. Leung JM, Sin DD. Asthma-COPD overlap syndrome: pathogenesis, clinical features, and therapeutic targets. BMJ 2017;358:j3772.

49. Tashkin DP, Celli B, Decramer M, Liu D, Burkhart D, Cassino C, Kesten S. Bronchodilator responsiveness in COPD. Eur Resp J 2008; 31(4):742-750.
50. Florin TA, Byczkowski T, Ruddy RM, Zorc JJ, Test M, Shah SS. Variation in the management of infants hospitalized for bronchiolitis persists after the 2006 American Academy of Pediatrics bronchiolitis guidelines. J Pediatr 2014;165(4):786-792.

51. Halfhide C1, Evans HJ, Couriel J. Inhaled bronchodilators for cystic fibrosis. Cochrane Database Syst Rev 2005;(4):CD003428.

52. Rubin BK. Pediatric aerosol therapy: new devices and new drugs. Respir Care 2011;56(9):1411-1421.

\section{Discussion}

MacIntyre: Let me start off. I find continuous aerosols to be a very confusing area. You pointed out that highdose $\beta$ agonists from continuous aerosol therapy likely saturate $\beta$ receptors, and thus may only promote toxicities. On the other hand, in the patient who is on a ventilator with an endotracheal tube full of mucus, delivery of a drug may be really compromised. The argument might be to use continuous aerosols there because it's so doggone difficult to get it down into the lungs. Does that make sense to you?

Rubin: You could make the same statement for giving systemic bronchodilators, because if the airway is blocked, don't you want to get medication to the airway by blood flow? And yes, that makes sense but you balance it with having a really sick patient on a mechanical ventilator who may be on neuromuscular blockade, who may have some cardiac abnormalities as well. These patients are often elderly, they're your COPDers, and are you willing to risk cardiovascular adverse effects? I don't think I've seen a formal risk-benefit study done. There's something else, since you brought up continuous nebulizations: Leslie Hendeles, who's a clinical pharmacist in Gainesville, has been interested in benzalkonium as a preservative for albuterol in multi-dose form. ${ }^{1}$ And it is a bronchoconstrictor. So, if you were using continuous nebulizers with a $\beta$ agonist like albuterol, you need to go preservative-free or you may be worsening bronchoconstriction.
Williams: The issue is that functionally in the pharmacy to prepare the solution for continuous nebulization would require opening a lot of single-use vials or ampules. There's been this trend toward using the multidose systems that contain benzalkonium chloride. The interesting thing is that we knew 12 years ago that benzalkonium chloride, if used in large enough doses, is a functional antagonist. There are reports of problems using multi-dose containers with benzalkonium where patients looked resistant or didn't do well with therapy, and it was attributed to the preservative.

Wechsler: Just a comment regarding the pharmacogenetics of $\beta$ agonists. You showed the LARGE study ${ }^{2}$ that we published as part of the Asthma Clinical Research Network and showed the global results. While subjects who had the Arg/Arg genotype had no significant improvement in peak flow with salmeterol in combination with inhaled corticosteroids, in the subset of AfricanAmerican subjects, there was a difference in $\beta$ agonist response based on genotype, and in the global population there were differences in airway hyper-responsiveness based on genotype. With regard to the African-American population, there were also differences in airway hyper-responsiveness. We just this week completed an AsthmaNet study of $>500$ subjects looking at inhaled steroids and LABAs in African-Americans. The last person finished their last visit this week, and we expect it will be analyzed and published next year. We are looking at genetic factors in terms of responsiveness to $\beta$ agonists in general.

Rubin: Fantastic. Really glad to have that update. One of the criticisms of the findings of the SMART trial ${ }^{3}$ was that a larger proportion of the subjects who had very bad outcomes were not on an inhaled corticosteroid. So the question is if you use a concomitant inhaled corticosteroid, will you abrogate some of the phenomenon that you see with the genotyping?

Wechsler: More recently there were a few different reports on different LABAs. ${ }^{4,5}$

Rubin: This is highly charged. As I recall, when all this was coming out there was a commentary by Salpeter et $\mathrm{al}^{6}$ who made the statement that more people had died from taking LABAs than had died from their asthma. That was much more inflammatory than any allergen I've seen.

Wise: You mentioned one of the barriers to using pressurized metered-dose inhalers (pMDIs) in the hospital compared to nebulizers is the cost. Some hospital are using single shared pMDIs between patients. The question I have is, what is the status of that, and is there any concern about cross-contamination?

Rubin: Yes, that's known as common canister. The concern with common canister usage is cross-contamination. There are disposable holding chambers that are fairly inexpensive that have been used under those circumstances for common canister use. I am not familiar with the latest ruling; I know the Joint Commission has 
been concerned about possible crosscontamination with that. We are not a common-canister institution, although we do not use nebulizers once patients are admitted to the hospital.

Peters: So I can't tell you the regulations, but in almost every hospital, the infection control committee will not allow you to use common canisters. Yet, as has been mentioned, we commonly use-in both the PFT lab as well as on the wards - the disposable cardboard holding chambers that have been cleared by all of our infection control committees.

Rubin: We're the same.

George: Going back to the SMART trial, ${ }^{3}$ I think we have to remember that there were other unique features in the African-American subjects who were enrolled in that study. They had lower $\mathrm{FEV}_{1}$, and they had more acute health care utilization. There were probably some things about the subjects they recruited that had more to do with their disease severity or psychosocial factors that may have also contributed to the higher death rates. Having been on the receiving side of all of that coming out, working predominantly in an African-American patient population, when all of this news started to hit and all of these patients started coming back and saying, "I'm going to stop taking the medicine you have me on," it really forced us to look deeply into the attributes of the subjects enrolled. And how to figure out the right messaging to encourage patients to continue on a therapy that we thought was really needed to control their asthma. I haven't worked in an acute care setting in a while, but I know that when we tried to transition away from nebulizer therapy in the hospital to a pMDI with a spacer, we got pushback from the payers, that if a patient was well enough to be treated in-patient with a pMDI and a valved holding chamber, then they were well enough to be discharged and go home. I wonder if you have any comments as to the payer side of this?

Rubin: We rarely encounter that. The response would be that we want patients out faster and we want them to do better, and for that reason we're using pMDIs.

George: Is it possible that it's regional or payer-specific?

Rubin: I can't understand why one would assume nebulizers are given to sicker patients. Unless you assume they're also receiving $\mathrm{O}_{2}$, but you could give $\mathrm{O}_{2}$ to someone with a pMDI as well. My suspicion is that it's the insurance company trying to find a way to not pay for something.

MacIntyre: Let me go back to that We have a protocol at Duke where patients come in and get assessed by an RT to see if they can even use a pMDI properly. You know as well as anybody, it does require a certain amount of skill and coordination to properly use a pMDI. Somebody like a tight asthmatic or with a COPD exacerbation, you'll have a devil of a time properly using the pMDI. Our protocol allows you to switch to a nebulizer for those kinds of patients until they are able to recover. Does that make sense?

Rubin: Anything you say makes sense. Well, I'm trying to avoid talking about my favorite subject, which is aerosol delivery clinically, because I know that will be covered. Maybe these questions can come up again for that presentation and discussion.

Strange: My observation is that we've done a really poor job of actually studying delivery of both $\beta$ agonists and anticholinergics in the hospital setting. You showed the metaanalysis showing no difference between intermittent albuterol and continuous nebulization, which just can't be true in all subsets of patients. We have all of these new drugs, none of which are being studied in the hospital setting. We' re not studying the transition to home, and all of these are obviously important for long-term care. I don't know how we break that barrier and get some of these studies actually funded and done. Do you have any observations? Our observers say these are really hard studies to do. Subjects get enrolled and leave the hospital quickly. You don't have the time to capture the important primary outcome measures.

Rubin: Again, I'm sure this will come up again later when we talk about clinical applications.

*Newhouse: I would like to comment on the issue of the cost of administering a pMDI and a valved holding chamber in the emergency department in the United States. I'll preface my remarks with the fact that nowhere else in the world are smallvolume nebulizers used for bronchodilation in the emergency department. And virtually every guideline, including that of the National Institutes of Health, ${ }^{7}$ says that the first-line treatment should be pMDI with a valved holding chamber. The issue about cost has been raised because there's this strange idea in the United States that, if you use a pMDI and a valved holding chamber, somehow contamination can occur from the boot of that device so that one pMDI cannot be used sequentially for several patients. Professor Leslie Hendeles at the University of Florida, Gainesville, showed me an excellent protocol that they have developed in which they can repeatedly use a pMDI and the boot is cleaned off appropriately with a cloth containing an antibacterial agent between insertions into the pMDI. Furthermore, because patients usually use a valved holding chamber, there is no contact between the pMDI mouthpiece and the patient. There's a study not yet published that has shown that, because of the more rapid response to multi-dose 
bronchodilators given by pMDI with a valved holding chamber, fewer patients are admitted to the hospital because they improve more quickly and more of them are sent home earlier. So if you take the cost of that into effect, it isn't more expensive to use a pMDI with a valved holding chamber, and indeed it's a good opportunity to teach patients how to use them while they're in the hospital with an exacerbation that they just recovered from and, I would surmise, are particularly amenable to being educated. Unsurprisingly, the reason that so many patients still request small-volume nebulizers for use at home is that they observe, as soon as they arrive in the ambulance or the emergency department, someone slaps a mask with aerosol from a nebulizer on their face. They get the idea that the pMDI with a valved holding chamber that they have at home is the kids' stuff, and the really good stuff is in that very obvious cloud of raindrops pouring out of the nebulizer. What needs to be done, in my view, is much better patient education based on the overwhelming evidence of therapeutic equivalence or superiority of the pMDI with a valved holding chamber, assuming that sufficient doses of the latter are administered-dose equivalents of about half of that given by nebulizer (ie, 500$1,000 \mu \mathrm{g}$ (5-10 puffs) by pMDI with a valved holding chamber $=$ approximately $1,000-2,500 \mu \mathrm{g}$ by a smallvolume nebulizer).

\section{REFERENCES}

1. Prabhakaran S, Abu-Hasan M, Hendeles L. Benzalkonium chloride: a bronchoconstricting preservative in continuous albuterol nebulizer solutions. Pharmacother 2017;37(5): 607-610.

2. Wechsler ME, Kunselman SJ, Chinchilli VM, Bleecker E, Boushey HA, Calhoun WJ, et al.; National Heart, Lung and Blood Institute's Asthma Clinical Research Network Effect of beta2-adrenergic receptor polymorphism on response to long-acting beta2 agonist in asthma (LARGE trial): a genotypestratified, randomized, placebo-controlled, crossover trial. Lancet 2009;374(9703): 1754-1764.

3. Nelson HS, Weiss ST, Bleecker ER, Yancey SW, Dorinsky PM; SMART Study Group. The Salmeterol Multicenter Asthma Research Trial: a comparison of usual pharmacotherapy for asthma or usual pharmacotherapy plus salmeterol. Chest 2006;129(1): $15-26$.

4. Stempel DA, Raphiou IH, Kral KM, Yeakey AM, Emmett AH, Prazma CM, et al.; for the AUSTRI Investigators. Serious asthma events with fluticasone plus salmeterol versus fluticasone alone. N Engl J Med 2016; 374(19):1822-1830.

5. Peters SP, Bleecker ER, Canonica GW, Park YB, Ramirez R, Hollis S, et al. Serious asthma events with budesonide plus formoterol vs budesonide alone. N Engl J Med 2016; 375(9):850-860.

6. Salpeter SR, Wall AJ, Buckley NS. Longacting beta-agonists with and without inhaled corticosteroids and catastrophic asthma events. Am J Med 2010;123(4): 322-328.

7. National Heart, Lung and Blood Institute. Asthma action plan. Publication no. 07-5251, April 2007.

* Michael T Newhouse MD, invited discussant. Dr Newhouse is chief medical officer for InspiRx.

This article is approved for Continuing Respiratory Care Education credit. For information and to obtain your CRCE

(free to AARC members) visit

www.rcjournal.com

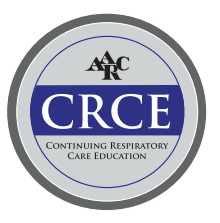

